Acta Crystallographica Section B

Structural

Science

ISSN 0108-7681

\title{
Temperature effects on the hydrogen-bond patterns in 4-piperidinecarboxylic acid
}

A temperature-controlled X-ray powder diffraction experiment, complemented with TGA and DSC analysis, allowed us to follow changes in the molecular conformation and hydrogen-bond patterns of 4-piperidinecarboxylic acid. The presence of three phases is confirmed. Phase 1 represents the monohydrated form of 4-piperidinecarboxylic acid, which exists from room temperature to $359 \mathrm{~K}$, where dehydration occurs. Phase 2 measured at $363 \mathrm{~K}$ corresponds to an anhydrous form of the acid. At $c a 458 \mathrm{~K}$ the onset of a second, more gradual transition is observed, which ends at around $543 \mathrm{~K}$. Phase 3 measured at $543 \mathrm{~K}$ is a hightemperature anhydrous form of the acid. The structures of phases 2 and 3 were solved from synchrotron powder diffraction data by simulated annealing using the $D A S H$ program and refined by the Rietveld method. The phase changes are accompanied by modification of the hydrogenbond patterns and of the torsional orientation of the terminal carboxylate group. This group makes a $49^{\circ}$ rotation about the $\mathrm{C} 1-\mathrm{C} 2$ bond during the first transition.

\section{Introduction}

Cooperative effects are involved in the formation of extended patterns of hydrogen bonds. In amino acids these effects are significant in the solid state and arise from a combination of polarization and charge transfer effects owing to the presence of strong carboxylate-amino $\left(-\mathrm{COO}^{-} \ldots{ }^{+} \mathrm{HN}-\right)$ intermolecular interactions (Glusker, 1996). The introduction of a polar medium, such as water, contributes further to the stabilization, as theoretical studies seem to point out, such as calculations performed on glycine (Jensen \& Gordon, 1995), alanine (Tajkhorshid et al., 1998), aspartic acid (Nagy \& Noszl, 2000) and 2-piperidine-carboxylic acid (Cuervo et al., 2002), in which water molecules were explicitly placed near the amino acids. Often amino acids crystallize as hydrates and the water itself is involved in the hydrogen-bond schemes. In such cases the presence of carboxylate-water $\left(-\mathrm{COO}^{-} \cdots \mathrm{H}_{2} \mathrm{O}\right)$ and amino-water $\left(-\mathrm{NH}^{+} \cdots \mathrm{H}_{2} \mathrm{O}\right)$ interactions are likely to induce changes in the structural conformation and functionality of amino acids. In a previous study (Mora et al., 2002) we investigated the room-temperature structure of 4-piperidinecarboxylic acid in its hydrate form by means of singlecrystal X-ray diffraction and solid-state NMR, focusing on the role played by hydrogen bonds. Semi-empirical calculations allowed us to evaluate the energies of formation of the two types of supramolecular structures present in the crystalline state of 4-piperidienecarboxylic acid: Extended chains of amino acid molecules linked by amino-carboxylate interac-
Received 16 September 2004 Accepted 30 November 2004
(C) 2005 International Union of Crystallography Printed in Great Britain - all rights reserved 
Table 1

Experimental details.

\begin{tabular}{|c|c|c|}
\hline & $363 \mathrm{~K}$ & $543 \mathrm{~K}$ \\
\hline \multicolumn{3}{|l|}{ Crystal data } \\
\hline Chemical formula & $\mathrm{C}_{6} \mathrm{H}_{11} \mathrm{NO}_{2}$ & $\mathrm{C}_{6} \mathrm{H}_{11} \mathrm{NO}_{2}$ \\
\hline$M_{r}$ & 129.16 & 129.16 \\
\hline Cell setting, space group & Looparray, $P n 2_{1} a$ & Looparray, $P 2_{1} 2_{1} 2_{1}$ \\
\hline$a, b, c(\AA)$ & $\begin{array}{l}10.8548(2), 9.7520(1), \\
\quad 6.1152(1)\end{array}$ & $\begin{array}{l}11.7537(5), 10.1013(5), \\
5.5787(2)\end{array}$ \\
\hline$\alpha, \beta, \gamma\left({ }^{\circ}\right)$ & $90,90,90$ & $90,90,90$ \\
\hline$V\left(\AA^{3}\right)$ & $647.32(2)$ & $662.35(5)$ \\
\hline$Z$ & 4 & 4 \\
\hline$D_{x}\left(\mathrm{Mg} \mathrm{m}^{-3}\right)$ & 1.325 & 1.295 \\
\hline Radiation type & Synchrotron & Synchrotron \\
\hline$\mu\left(\mathrm{mm}^{-1}\right)$ & 0.170 & 0.166 \\
\hline Temperature (K) & 363 & 543 \\
\hline Specimen form, colour & $\begin{array}{l}\text { Cylinder (particle } \\
\text { morphology: thin } \\
\text { powder), white }\end{array}$ & $\begin{array}{l}\text { Cylinder (particle } \\
\text { morphology: thin } \\
\text { powder), white }\end{array}$ \\
\hline Specimen size $(\mathrm{mm})$ & $40.0 \times 1.5 \times 1.5$ & $40.0 \times 1.5 \times 1.5$ \\
\hline $\begin{array}{l}\text { Specimen preparation } \\
\text { cooling rate }\left(\mathrm{K} \mathrm{min}^{-1}\right)\end{array}$ & 2 & 2 \\
\hline $\begin{array}{l}\text { Specimen preparation pres- } \\
\text { sure }(\mathrm{kPa})\end{array}$ & None & None \\
\hline $\begin{array}{l}\text { Specimen preparation } \\
\text { temperature }(\mathrm{K})\end{array}$ & 298 & 298 \\
\hline \multicolumn{3}{|l|}{ Data collection } \\
\hline Diffractometer & Inet & Inet \\
\hline Data collection method & $\begin{array}{l}\text { Specimen mounting: borosi- } \\
\text { licate glass capillary; } \\
\text { mode: transmission; scan } \\
\text { method: continuous }\end{array}$ & $\begin{array}{l}\text { Specimen mounting: borosi- } \\
\text { licate glass capillary; } \\
\text { mode: transmission; scan } \\
\text { method: continuous }\end{array}$ \\
\hline Absorption correction & None & None \\
\hline $2 \theta\left(^{\circ}\right)$ & $\begin{array}{l}2 \theta_{\min }=0.50966,2 \theta_{\max }= \\
0.90466, \text { increment }=0.005\end{array}$ & $\begin{array}{l}2 \theta_{\min }=0.50228,2 \theta_{\max }= \\
0.89728, \text { increment }=0.005\end{array}$ \\
\hline \multicolumn{3}{|l|}{ Refinement } \\
\hline Refinement on & $I_{\text {net }}$ & $I_{\text {net }}$ \\
\hline$R$ factors and goodness-of-fit & $\begin{array}{l}R_{p}=0.061, R_{\mathrm{wp}}=0.080 \\
\quad R_{\exp }=0.034, S=2.37\end{array}$ & $\begin{array}{l}R_{p}=0.090, R_{\mathrm{wp}}=0.132 \\
\quad R_{\exp }=0.058, S=2.29\end{array}$ \\
\hline $\begin{array}{l}\text { Wavelength of incident } \\
\text { radiation }(\AA)\end{array}$ & $0.33497(6)$ & $0.33497(6)$ \\
\hline Excluded region(s) & None & None \\
\hline Profile function & $\begin{array}{l}\text { CW Profile function number } \\
3 \text { with } 19 \text { terms }\end{array}$ & $\begin{array}{l}\text { CW Profile function number } \\
3 \text { with } 19 \text { term }\end{array}$ \\
\hline No. of parameters & 94 & 94 \\
\hline $\mathrm{H}$-atom treatment & Constrained to parent site & Constrained to parent site \\
\hline Weighting scheme & Looparray & Looparray \\
\hline$(\Delta / \sigma)_{\max }$ & 0.04 & 0.030 \\
\hline
\end{tabular}

Computer programs used: GSAS (Larson \& Von Dreele, 2001), EXPGUI (Toby, 2001), DASH (David et al., 2001), DIAMOND (Brandenburg, 1998), PLATON (Spek, 2003).

tions, and extended bent chains of amino acid molecules intercalated with water molecules held together by carboxylate-water interactions. The theoretical calculations show large cooperative effects for the first type of chain, but they are less significant for those involving water molecules. This result is supported by the fact that in the hydrogen bonds formed in these chains, the water molecule acts only as a double donor of $\mathrm{H}$ atoms and not as a double donor-double acceptor as seen in clusters of water (Rincón et al., 2001), water-methanol (Mó et al., 1992) and hydrogen peroxidewater (Mó et al., 1994). At this point the need was evident to perform experiments to follow changes induced in the structure and the hydrogen bonds by temperature increments. Here we report the results of TGA (thermal gravimetric analysis), DSC (differential scanning calorimetry) and temperature-controlled X-ray powder diffraction experiments performed on 4-piperidinecarboxylic acid monohydrate.

\section{Experimental}

Thermogravimetric Analysis (TGA) of 4-piperidinecarboxylic acid monohydrate was performed in a PerkinElmer TGA7 thermobalance. A sample of $5.9 \mathrm{mg}$ of the amino acid was placed in an aluminium pan and heated from 298 to $573 \mathrm{~K}$ at a rate of $10 \mathrm{~K} \mathrm{~min}^{-1}$, under a nitrogen flux of $50 \mathrm{ml} \mathrm{min}^{-1}$. For the DSC experiment, a sample of $4.0 \mathrm{mg}$ contained in an aluminium vessel was placed inside a Perkin-Elmer DSC7 oven and heated at a rate of $10 \mathrm{~K} \mathrm{~min}^{-1}$ using the same temperature range and nitrogen flux as above.

The temperature controlled X-ray powder diffraction experiment was performed on the high-resolution powder X-ray diffractometer of beamline ID31 at ESRF (Fitch, 1996, 2004) with a wavelength of 0.33497 (6) A. Sufficient quantities of 4-piperidinecarboxylic acid were loaded at room temperature into a $1.5 \mathrm{~mm}$ diameter borosilicate thinwalled glass capillary, spun at approximately $1 \mathrm{~Hz}$, and heated by means of a hot air blower (Argoud \& Capponi, 1984) mounted vertically, perpendicular to the capillary. The progression of the sample through the crystalline phase transitions, from room temperature to the melting point, was observed by recording patterns every $120 \mathrm{~s}$ in the $2 \theta$ range $0-16^{\circ}$, while warming at $2 \mathrm{~K} \mathrm{~min}^{-1}$. Diffraction patterns were also collected at 363 and $543 \mathrm{~K}$ for $2 \mathrm{~h}$ scan. Full experimental details are given in Table 1.1

\section{Results}

Fig. 1(a) shows the TGA for 4-piperidinecarboxylic acid monohydrate. A maximum at $359 \mathrm{~K}$, with a mass loss of $11.9 \%$, corresponds to the dehydration process. A second

\footnotetext{
${ }^{1}$ Supplementary data for this paper are available from the IUCr electronic archives (Reference: AV5021). Services for accessing these data are described at the back of the journal.
} 
broad maximum at $582 \mathrm{~K}$, with a mass loss of $83.2 \%$, is associated with the melting and decomposition of the amino acid. The DSC of Fig. 1(b) shows the dehydration as an endothermic process, with an enthalpy change of $37.9 \mathrm{~kJ} \mathrm{~mol}^{-1}$. After dehydration, the baseline of the thermogram rises owing to a change in the molar heat capacity $(C P)$ of the compound. At $c a 543 \mathrm{~K}$ the baseline falls, indicating an exothermic process associated with melting and decomposition of the amino acid and in agreement with the TGA experiment.

Fig. 2 shows the three-dimensional plot of the diffraction profiles versus temperature. Three crystalline phases were immediately identified. The first phase exists from room temperature to $c a 353 \mathrm{~K}$; the second phase exists up to $493 \mathrm{~K}$, while the third phase appears at $458 \mathrm{~K}$. The phase at room temperature corresponds to 4-piperidinecarboxylic acid monohydrate, $\mathrm{C}_{6} \mathrm{H}_{11} \mathrm{NO}_{2} \cdot \mathrm{H}_{2} \mathrm{O}$. This phase was reported previously (Delgado et al., 2001) in an orthorhombic Pna2 (No. 33) cell, with parameters $a=11.9647$ (11), $b=8.3276$ (7),

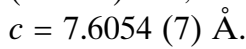

The diffraction pattern collected at $363 \mathrm{~K}$ was indexed in an orthorhombic cell, $a=10.862$ (2), $b=9.755$ (1), $c=6.119$ (1) $\AA$, from the positions of the first 20 peaks using DICVOL91 (Boultif \& Louër, 1991), with figures of merit $M_{20}$ (De Wolff, 1968) of 63.3 and $F_{20}$ (Smith \& Snyder, 1979) of 511. Evaluation of the systematic absences in the diffraction pattern indicated the space group $P n 2_{1} a$ (No. 33), with $Z=4$ and one molecule in the asymmetric unit. The structure was
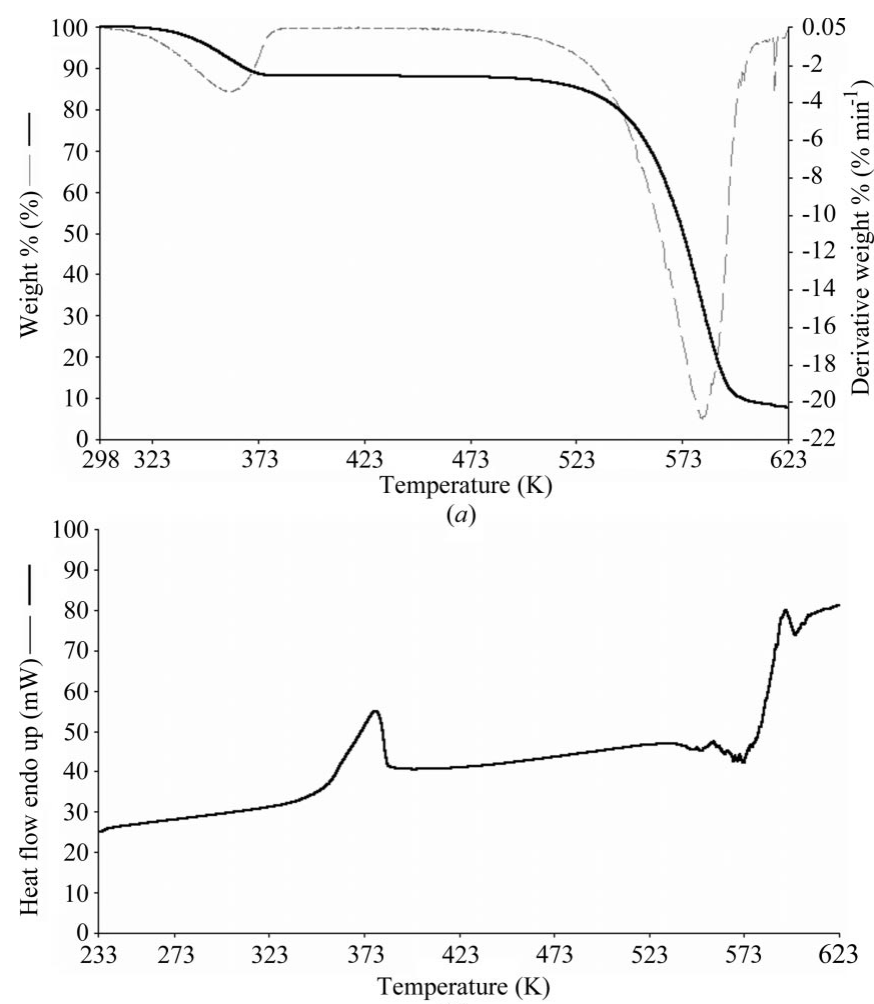

(b)

Figure 1

(a) TGA (broken line: mass loss; continous line: mass loss velocity) and (b) DSC for 4-piperidinecarboxylic acid. solved using the simulated annealing program $D A S H$ (David et al., 2001). The amino acid fragment of the room-temperature phase (Delgado et al., 2001) was used as the starting model. This implied that seven parameters were to be found during minimization: three coordinates to describe the position of the centre of mass of the molecule and four quaternions describing its orientation. The simulated annealing program was set in default mode, with the number of runs fixed at ten. All the solutions arrived at the same minimum $\left(\chi^{2}=44.1\right.$, approximately four times the Pawley $\left.\chi^{2}\right)$. The structure was allowed to refine using Rietveld's (Rietveld, 1969) program GSAS (Larson \& Von Dreele, 2001; Toby, 2001), with 59 restraints distributed in the following manner: 20 bond-distance restraints, 38 angle restraints and 1 planar restraint applied to the carboxylate group. The initial values for bond distances and angles were taken from the roomtemperature structure, weighted by $0.02 \AA$ and $2^{\circ}$, respectively. $\mathrm{H}$ atoms were refined with $\mathrm{C}-\mathrm{H}, \mathrm{N}-\mathrm{H}$ distances restrained to be $0.990 \AA$ and weighted by $0.01 \AA$. The background was described by the automatic linear interpolation of 20 points throughout the whole pattern. The peak shapes were described by an anisotropic parameterized pseudo-Voigt peak shape function (van Laar \& Yelon, 1984; Stephens, 1999), which includes an axial divergence asymmetry correction (Finger et al., 1994). The temperature factors were refined as follows: one overall isotropic temperature factor for non- $\mathrm{H}$ atoms, except the carboxylate group, whose motion was described by a separate isotropic temperature factor. $\mathrm{H}$ atoms were refined as riding atoms with their temperature factors set to twice the value of the attached non-H atom. The refinement of 94 variables converged to $R_{\mathrm{wp}}=0.080$ and $\chi^{2}=5.60$. The observed, calculated and difference profiles of the final fit are shown in Fig. 3.

The diffraction pattern collected at $543 \mathrm{~K}$ was also indexed from the positions of the first 20 peaks using DICVOL91 (Boultif \& Louër, 1991), $a=11.752$ (1), $b=10.105$ (3), $c=$ 5.5775 (8) $\AA$, with figures of merit $M_{20}=39.9$ (De Wolff, 1968)

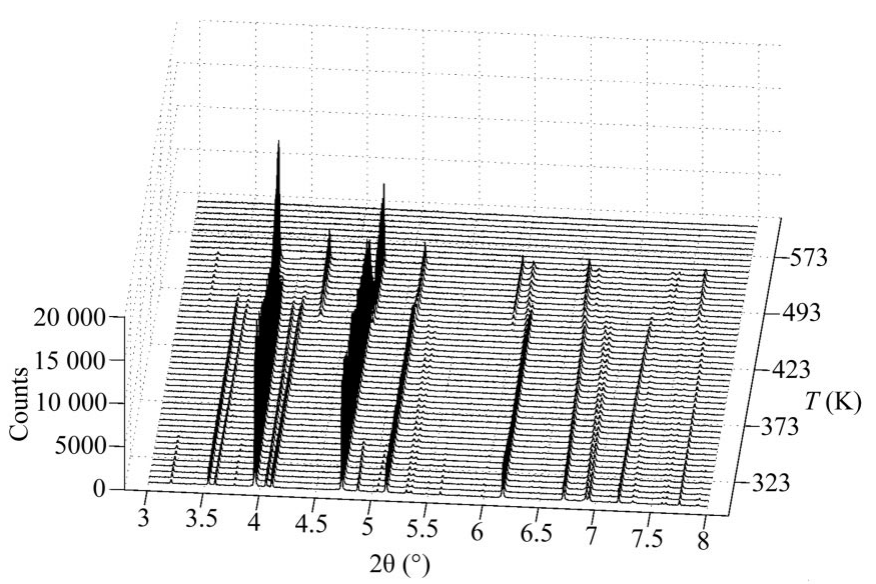

Figure 2

Three-dimensional temperature-dependent X-ray diffraction plot for 4piperidinecarboxylic acid. 
and $F_{20}=256$ (Smith \& Snyder, 1979). Evaluation of systematic absences indicated the space group $P 2_{1} 2_{1} 2_{1}$ (No. 19). The structure was solved using the program $D A S H$ (David et al., 2001), following the same procedure as described above. On this occasion, the solutions arrived at a minimum with $\chi^{2}=21.7$, approximately five times the Pawley $\chi^{2}$. In order to compare this structure to the same standard with 4piperidinecarboxylic acid monohydrate (phase 1) and anhydrous 4-piperidinecarboxylic acid (phase 2), the Rietveld refinement (Rietveld, 1969) with the program GSAS was carried out following strictly the same procedure as described above. The final agreement factors were $R_{\mathrm{wp}}=0.132$ and $\chi^{2}=$ 5.23. It is likely that two major factors are responsible for the slightly high $R_{\mathrm{wp}}$ reported for the refinement of phase 3:

(a) changes in sample mass during the diffraction data collection due to decomposition and

(b) poor modelling of thermal motion at such high temperature.

The observed, calculated and difference profiles of the final fit are shown in Fig. 4. Table 2 contains selected torsion angles for the three phases.

\section{Discussion}

Comparison of the temperature-dependent experiments TGA, DSC and X-ray diffraction confirms the existence of three crystalline phases for 4-piperidenecarboxylic acid. Phase 1 corresponds to 4-piperidinecarboxylic acid monohydrate, which prevails from room temperature to $353 \mathrm{~K}$. At this temperature an endothermic transition $(\Delta H=$ $+37.9 \mathrm{~kJ} \mathrm{~mol}^{-1}$ ) occurs, whose mass loss exactly matches the removal from the crystalline phase 1 of four molecules of water per unit cell with the corresponding cell-volume contraction of $111 \AA^{3}$. Hence, phase 2 represents an anhydrous form of 4-piperidinecarboxylic acid. Another phase transition, observed only in the temperature-controlled X-ray experiment, initiates at around $458 \mathrm{~K}$. This second phase transition does not involve mass loss and arises from an additional reordering of the molecules with a $15.0 \AA^{3}$ expansion of the cell. Therefore, phase 3 represents another anhy-

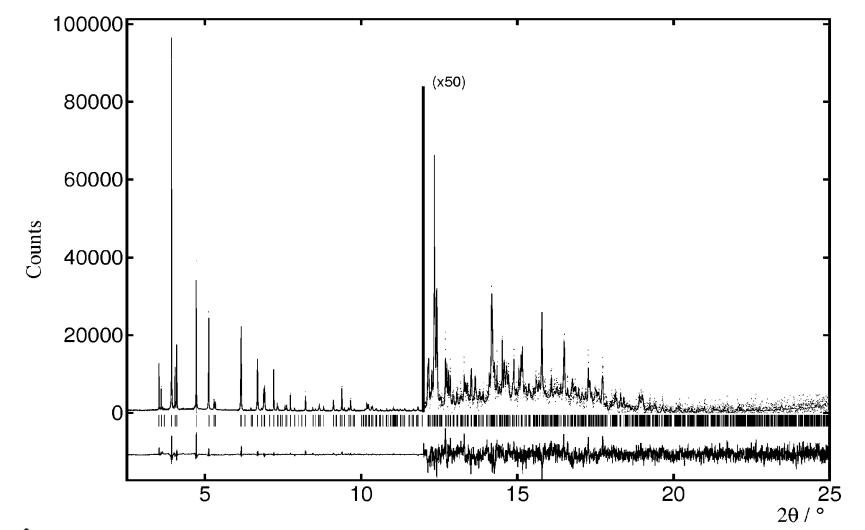

Figure 3

Rietveld refinement for anhydrous 4-piperidinecarboxylic acid at $363 \mathrm{~K}$ (phase 2).
Table 2

Bond distances $(\AA)$ and angles $\left({ }^{\circ}\right)$.

\begin{tabular}{|c|c|c|c|}
\hline & Phase 2 & & Phase 3 \\
\hline $\mathrm{O} 1-\mathrm{C} 1$ & $1.252(9)$ & & $1.19(2)$ \\
\hline $\mathrm{O} 2-\mathrm{C} 1$ & $1.312(9)$ & & $1.21(2)$ \\
\hline $\mathrm{N} 1-\mathrm{C} 4$ & $1.51(2)$ & & $1.49(3)$ \\
\hline $\mathrm{N} 1-\mathrm{C} 5$ & $1.41(1)$ & & $1.48(3)$ \\
\hline $\mathrm{C} 1-\mathrm{C} 2$ & $1.56(1)$ & & $1.55(2)$ \\
\hline $\mathrm{C} 2-\mathrm{C} 3$ & $1.51(2)$ & & $1.52(3)$ \\
\hline $\mathrm{C} 2-\mathrm{C} 6$ & $1.50(2)$ & & $1.55(4)$ \\
\hline $\mathrm{C} 3-\mathrm{C} 4$ & $1.57(2)$ & & $1.59(4)$ \\
\hline $\mathrm{C} 5-\mathrm{C} 6$ & $1.56(2)$ & & $1.55(4)$ \\
\hline $\mathrm{C} 4-\mathrm{N} 1-\mathrm{C} 5$ & $117.6(8)$ & & $121(2)$ \\
\hline $\mathrm{O} 1-\mathrm{C} 1-\mathrm{O} 2$ & $122.8(7)$ & & $120(2)$ \\
\hline $\mathrm{O} 1-\mathrm{C} 1-\mathrm{C} 2$ & $121.8(7)$ & & $119(2)$ \\
\hline $\mathrm{O} 2-\mathrm{C} 1-\mathrm{C} 2$ & $115.4(6)$ & & $121(2)$ \\
\hline $\mathrm{C} 1-\mathrm{C} 2-\mathrm{C} 3$ & $107.5(9)$ & & $113(2)$ \\
\hline $\mathrm{C} 1-\mathrm{C} 2-\mathrm{C} 6$ & $111.5(9)$ & & $106(2)$ \\
\hline $\mathrm{C} 3-\mathrm{C} 2-\mathrm{C} 6$ & $111.2(8)$ & & $121(2)$ \\
\hline $\mathrm{C} 2-\mathrm{C} 3-\mathrm{C} 4$ & $107.5(9)$ & & $106(2)$ \\
\hline $\mathrm{N} 1-\mathrm{C} 4-\mathrm{C} 3$ & $108.3(9)$ & & $113(2)$ \\
\hline $\mathrm{N} 1-\mathrm{C} 5-\mathrm{C} 6$ & $105(1)$ & & $111(2)$ \\
\hline $\mathrm{C} 2-\mathrm{C} 6-\mathrm{C} 5$ & $112.3(9)$ & & $109(2)$ \\
\hline Torsion angles $\left(^{\circ}\right)$ & Phase 1 & Phase 2 & Phase 3 \\
\hline $\mathrm{O} 1-\mathrm{C} 1-\mathrm{C} 2-\mathrm{C} 3$ & 178.5 & $134(1)$ & $-137(2)$ \\
\hline $\mathrm{O} 1-\mathrm{C} 1-\mathrm{C} 2-\mathrm{C} 6$ & $-57.5(3)$ & $-104(1)$ & $89(2)$ \\
\hline $\mathrm{O} 2-\mathrm{C} 1-\mathrm{C} 2-\mathrm{C} 3$ & $-2.1(3)$ & $-49(1)$ & $50(3)$ \\
\hline $\mathrm{O} 2-\mathrm{C} 1-\mathrm{C} 2-\mathrm{C} 6$ & 121.9 & $73(1)$ & $-85(3)$ \\
\hline
\end{tabular}

drous high-temperature form of 4-piperidenecarboxylic acid. Fig. 5 shows the atom labelling scheme for the two anhydrous forms of 4-piperidinecarboxyilic acid. Fig. 6 shows an assessment of the molecular conformation of the three crystalline phases. As expected, phase 2 adopts the chair conformation, similar to that observed at room temperature for 4-piperidinecarboxylic acid monohydrate, phase 1 (Delgado et al., 2001), and in the related crystal structures 2-piperidinecarboxylic acid (Bhattacharjee \& Chacko, 1979) and 3piperidinecarboxylic acid (Brehm et al., 1976). The carboxylate group is equatorial to the ring, with $\mathrm{N} 1$ and $\mathrm{C} 2$ placed on opposite sides of the mean plane of the piperidine ring, 0.229 and $0.265 \AA$, respectively. The orientation of the carboxylate

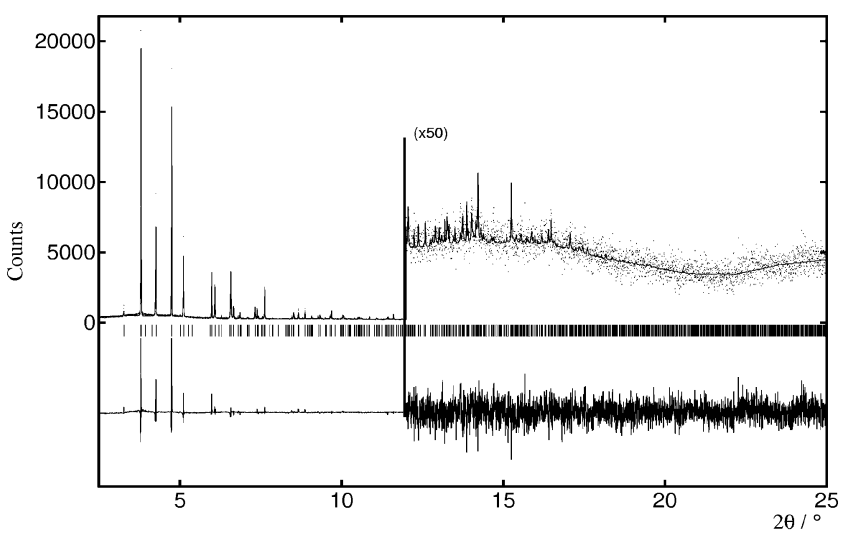

Figure 4

Rietveld refinement for anhydrous 4-piperidinecarboxylic acid at $543 \mathrm{~K}$ (phase3). 
Table 3

Geometries of hydrogen bonds $\left(\AA,^{\circ}\right)$.

\begin{tabular}{|c|c|c|c|c|}
\hline$D-\mathrm{H} \cdots A$ & $D-\mathrm{H}$ & $\mathrm{H} \cdots A$ & $D \cdots A$ & $D-\mathrm{H}^{\prime} \cdots$ \\
\hline \multicolumn{5}{|c|}{ Phase 1: 4-piperidinecarboxylic acid monohydrate $\dagger$} \\
\hline $\mathrm{N} 1-\mathrm{H} 10 \cdots \mathrm{O} 1^{\mathrm{i}}$ & $0.89(4)$ & $1.86(4)$ & $2.744(3)$ & $175(4)$ \\
\hline $\mathrm{N} 1-\mathrm{H} 11 \cdots \mathrm{O} 2^{\mathrm{ii}}$ & $0.94(4)$ & $1.85(4)$ & $2.776(3)$ & $169(3)$ \\
\hline $\mathrm{O} 3-\mathrm{H} 12 \cdots \mathrm{O} 2^{\mathrm{iii}}$ & $0.87(8)$ & $1.97(7)$ & $2.752(4)$ & $149(8)$ \\
\hline $\mathrm{O} 3-\mathrm{H} 13 \cdots \mathrm{O} 1^{\mathrm{ii}}$ & $0.85(7)$ & $2.06(6)$ & $2.862(4)$ & $157(7)$ \\
\hline \multicolumn{5}{|c|}{ Phase 2: 4-piperidinecarboxylic acid dihydrate } \\
\hline $\mathrm{N} 1-\mathrm{H} 10 \cdots \mathrm{O} 1^{\mathrm{iv}}$ & $0.97(3)$ & $1.77(2)$ & $2.720(8)$ & $164(3)$ \\
\hline $\mathrm{N} 1-\mathrm{H} 11 \cdots \mathrm{O} 2^{\mathrm{v}}$ & $0.97(2)$ & $1.95(3)$ & $2.725(8)$ & $135(3)$ \\
\hline $\mathrm{C} 2-\mathrm{H} 1 \cdots \mathrm{O} 2^{\mathrm{vi}}$ & $1.07(3)$ & $2.36(2)$ & $3.426(9)$ & $170(2)$ \\
\hline $\mathrm{C} 5-\mathrm{H} 6 \cdots \mathrm{O} 2^{\mathrm{vii}}$ & $0.98(3)$ & $2.60(3)$ & 3. 49 (1) & $151(2)$ \\
\hline \multicolumn{5}{|c|}{ Phase 3: Anhydrous 4-piperidinecarboxylic acid (high temperature). } \\
\hline $\mathrm{N} 1-\mathrm{H} 10 \cdots \mathrm{O} 1^{\text {viii }}$ & $0.98(4)$ & $2.38(4)$ & $3.30(2)$ & $155(4)$ \\
\hline $\mathrm{N} 1-\mathrm{H} 10 \cdots \mathrm{O} 2^{\mathrm{ix}}$ & $0.98(4)$ & $2.14(5)$ & $3.00(2)$ & $145(4)$ \\
\hline $\mathrm{N} 1-\mathrm{H} 11 \cdots \mathrm{O} 1^{\mathrm{ix}}$ & $0.98(5)$ & $1.88(5)$ & $2.82(2)$ & $158(5)$ \\
\hline $\mathrm{C} 2-\mathrm{H} 1 \cdots \mathrm{O} 2^{\mathrm{x}}$ & $1.09(4)$ & $2.39(3)$ & $3.42(2)$ & 157 (4) \\
\hline
\end{tabular}

$\dagger$ Taken from Delgado et al. (2001). Symmetry codes: (i) $\frac{1}{2}-x, \frac{1}{2}+y,-\frac{1}{2}+z$; (ii) $x, y,-1+z$; (iii) $\frac{1}{2}+x, \frac{1}{2}-y,-1+z$; (iv) $x, y, 1+z$; (v) $-\frac{1}{2}+x, y, \frac{1}{2}-z$; (vi) $-\frac{1}{2}+x, y,-\frac{1}{2}-z ; \quad$ (vii) $\quad \frac{1}{2}-x, \frac{1}{2}+y, \frac{1}{2}+z ; \quad$ (viii) $\quad-\frac{1}{2}+x, \frac{1}{2}-y, 1-z$; $\quad$ (ix) $-\frac{1}{2}+x, \frac{1}{2}-y,-z ;$ (x) $x, y,-1+z$.

group is described by the torsion angles contained in Table 2. In essence, the most prominent variation at a molecular level detected in this phase corresponds to the orientation of the carboxylate group with respect to the piperidine ring. At room temperature this group adopts an almost coplanar orientation with respect to the piperidine mean plane, as described by the torsion angle $\mathrm{O} 2-\mathrm{C} 1-\mathrm{C} 2-\mathrm{C} 6122^{\circ}$. Once the water molecules split away, breaking carboxylate-water hydrogen bonds, the carboxylate group rotates $49^{\circ}$ clockwise about the $\mathrm{C} 1-\mathrm{C} 2$ bond, as denoted by the value of the torsion angle $\mathrm{O} 2-\mathrm{C} 1-$ $\mathrm{C} 2-\mathrm{C} 673^{\circ}$. In phase 3 few deviations from the molecular conformation of phase 2 are perceived. The orientation of the carboxylate group is kept as shown by the corresponding torsion angles of Table 2, and by the positions of $\mathrm{N} 1$ and $\mathrm{C} 2$, also positioned on different sides of the mean plane of the piperidine ring at 0.195 and $0.231 \AA$, respectively.

Hydrogen bonds for the three phases of 4-piperidinecarboxylic acid are summarized in Table 3. The projection of the crystal packing of 4-piperidinecarboxylic acid monohydrate at room temperature is presented elsewhere

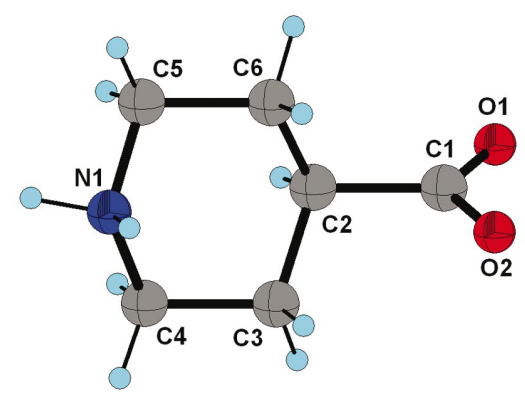

Figure 5

Labelling scheme for anhydrous 4-piperidinecarboxylic acid (phases 2 and 3).
(Delgado et al., 2001). Two supramolecular types of structures are recognized. Extended chains of amino acid molecules linked by $\mathrm{NH}_{2}^{+} \ldots \mathrm{COO}^{-}$hydrogen bonds run along $\mathbf{b}$ and $\mathbf{c}$. Additionally, extended bent chains of amino acid molecules, intercalated with water molecules linked by $\mathrm{H}_{2} \mathrm{O} \cdots \mathrm{COO}^{-}$ hydrogen bonds, run parallel to a. A combination of all the interactions forms a three-dimensional assembly of hydrogen bonds, in which the amino group acts as a donor to both its $\mathrm{H}$ atoms, while the carboxylate acts as an acceptor of four $\mathrm{H}$ atoms, two from amino groups of neighbouring amino acid molecules and two from water molecules. In Fig. 7 projection down $\mathbf{c}$ of phase 1 shows a 25-atom cycle constructed from hydrogen bonds among five amino acids and two water molecules. When water leaves, breaking the $\mathrm{H}_{2} \mathrm{O} \cdots \mathrm{COO}^{-}$ hydrogen bonds, a reordering of the structure occurs to fill the empty space left by the water molecules.

In fact, packing is improved in phase 2 and the filled space amounts to $72.1 \%$, in contrast with $69.2 \%$ for phase 1 . Fig. 8 is a projection down b showing a 20 -atom cycle formed by hydrogen bonds among four amino acid molecules. Evaluation of the hydrogen bonds contained in Table 3 indicates that the

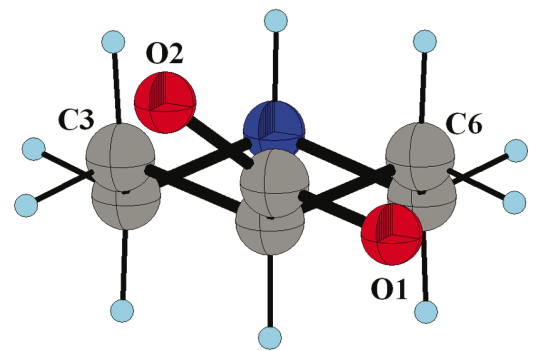

(a)

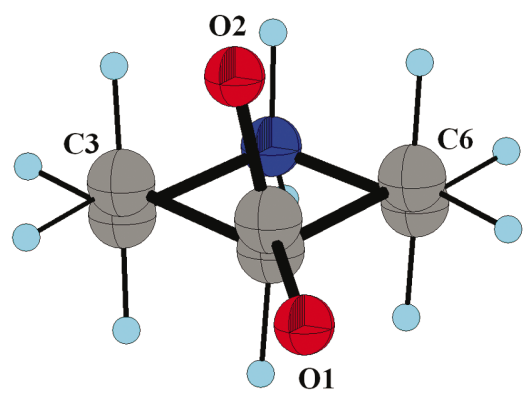

(b)

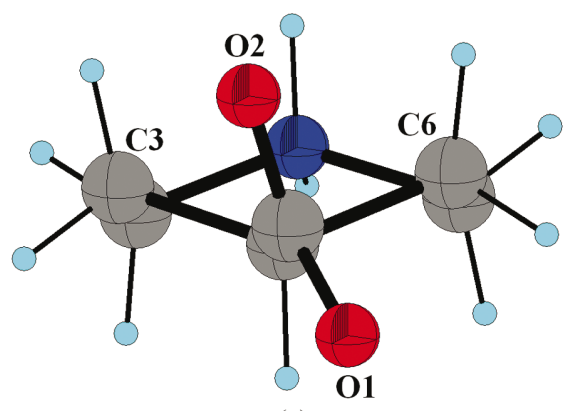

(c)

Figure 6

Orientation of the carboxylate group with respect to the piperidine ring in 4-piperidinecarboxylic acid (a) monohydrate (293 K), (b) anhydrous $(363 \mathrm{~K})$ and $(c)$ anhydrous $(543 \mathrm{~K})$. 
H-atom donor capacity of the amino group is 2, donating its two $\mathrm{H}$ atoms to $\mathrm{O}$ atoms of carboxylate groups of amino acids located in the vicinity. On the other hand, the packing of molecules is such as to guarantee the interaction of $\mathrm{O} 2$ with neighbouring amino acids by means of two $\mathrm{O} \cdots \mathrm{H}-\mathrm{C}$ weak hydrogen bonds. In this way, the carboxylate group completes its acceptor capacity. Fig. 9 shows the layered nature of the structure, where a stack of these layers related by $2_{1}$ axes down b is displayed. The weak hydrogen bonds $\mathrm{C} 5-\mathrm{H} 6 \cdots \mathrm{O} 2$ of $2.39 \AA$ between molecules related by $\frac{1}{2}-x, \frac{1}{2}+y, \frac{1}{2}+z$ translations act as anchors and maintain the layered packing of the structure. The counterparts of these hydrophilic interactions are hydrophobic interactions of the type $\mathrm{C}-\mathrm{H} \cdots \mathrm{H}-\mathrm{C}$, the shortest of these interactions being the one corresponding to H2 . H $2.53 \AA$ A between amino acid molecules related by the translation operation $\frac{1}{2}-x, \frac{1}{2}+y, \frac{1}{2}+z$.

Upon heating, the amino acid molecules require additional space to accommodate thermal motion and hence, elongation

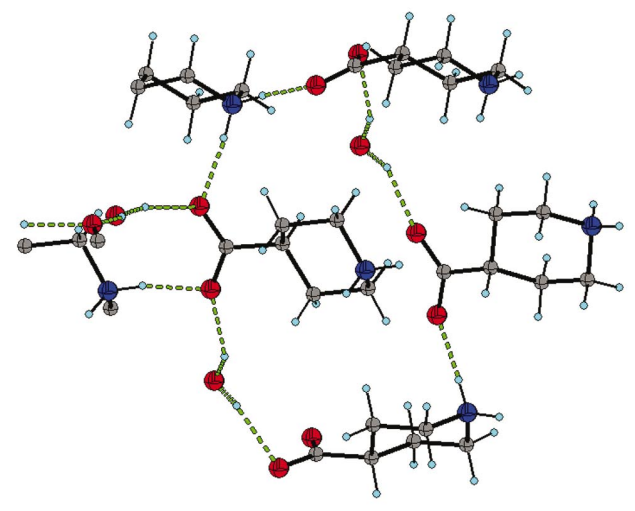

Figure 7

Projection down $\mathbf{c}$ of 4-piperidinecarboxylic acid monohydrate at $293 \mathrm{~K}$ (phase 1) showing the 25-atom cycle constructed from hydrogen bonds among five amino acids and two water molecules.

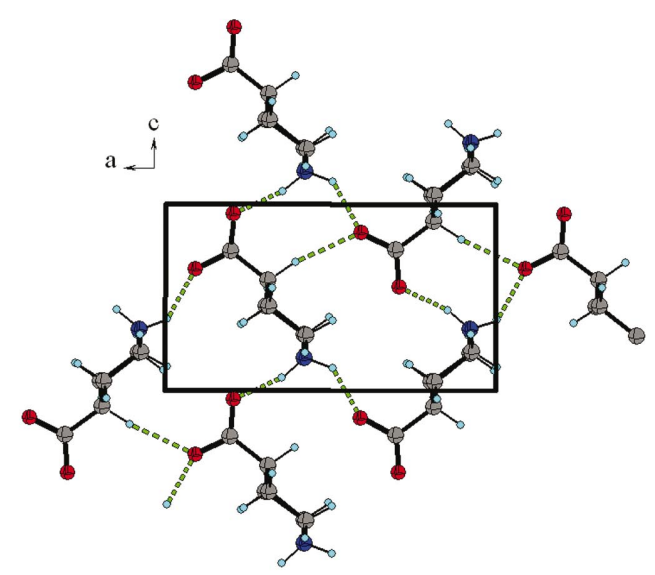

Figure 8

Projection down b of anhydrous 4-piperidinecarboxylic acid at $363 \mathrm{~K}$ (phase 2), displaying the 20-atom cycle of four hydrogen-bonded amino acids. of the hydrogen bonds occurs. Furthermore, small oscillations of the amino acid molecules from the equilibrium positions attained in the crystalline structure of phase 2 produce a redistribution of the hydrogen bonds, in which, in a concerted way, some hydrogen bonds break and others appear. The modification of the hydrogen bonds gives rise to the hightemperature phase 3 . A packing view of phase 3 down $b$ is shown in Fig. 10. The geometries of the hydrogen bonds are depicted in Table 3. It is interesting to point out that even at $543 \mathrm{~K}$, a temperature close to the melting point of the amino acid, the donor and acceptor capacities of the amino and carboxylate groups are kept. For instance, packing must favour the geometries of the bifurcated donor $\mathrm{N} 1-\mathrm{H} 10 \cdots \mathrm{O} 2$ and $\mathrm{C} 2-\mathrm{H} 1 \cdots \mathrm{O} 2$ hydrogen bonds to complete the acceptor capacity of $\mathrm{O} 2$.

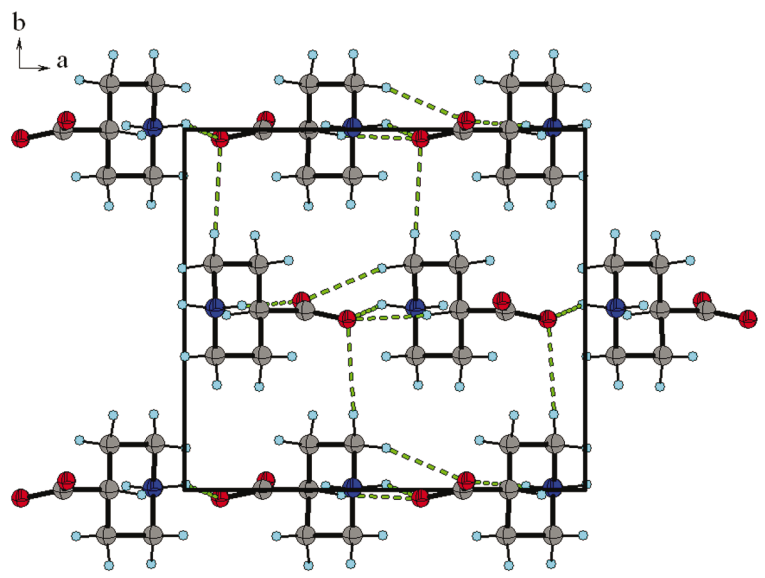

Figure 9

Projection down $\mathbf{c}$ of anhydrous 4-piperidinecarboxylic acid at $363 \mathrm{~K}$ (phase 2).

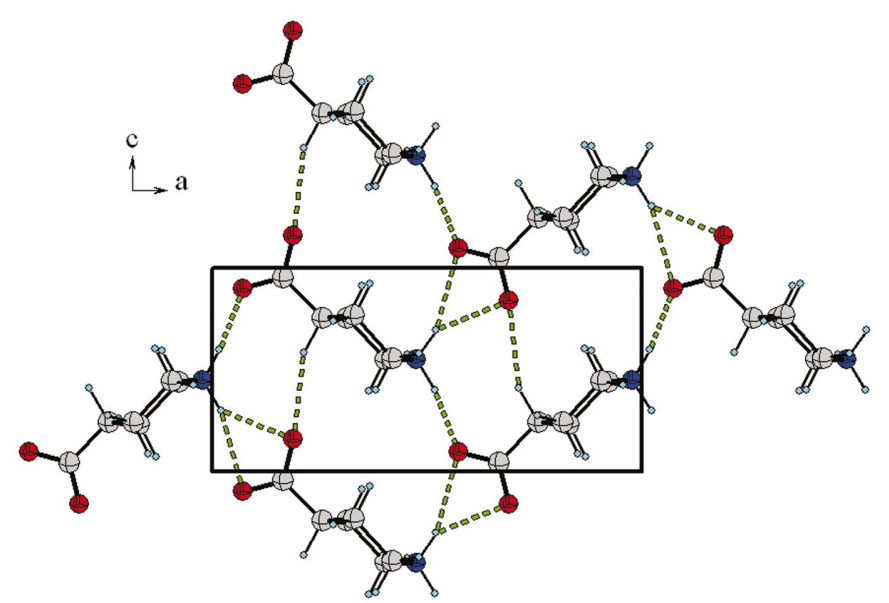

Figure 10

Projection down b of anhydrous 4-piperidinecarboxylic acid at $543 \mathrm{~K}$ (phase 3). 


\section{Concluding remarks}

A temperature-controlled X-ray powder diffraction experiment, complemented with TGA and DSC analysis, allowed us to follow changes in the molecular conformation and hydrogen-bond patterns of 4-piperidinecarboxylic acid. It is perceived that progression through the phase changes is accompanied by the concerted rupture and formation of hydrogen bonds, with the subsequent modification of the torsional orientation of the terminal carboxylate group. However, regardless of temperature, stabilization of a phase requires that the amino group donate both its $\mathrm{H}$ atoms for hydrogen bonding, while the carboxylate group must participate as an acceptor in the formation of at least four hydrogen bonds. This pseudo-coordination rule is evidence of the highly covalent and directional character of the hydrogen bonds in amino acids.

We thank the ESRF for providing synchrotron radiation beamtime, FONACIT-Venezuela and CDCHT-ULA (Grant C-990-99-08-AA), and M. Sc. Carlos Torres for the TGA and DSC experiments.

\section{References}

Argoud, R. \& Capponi, J. J. (1984). J. Appl. Cryst. 17, 420425.

Bhattacharjee, S. K. \& Chacko, K. K. (1979). Acta Cryst. B35, 396398.

Boultif, A. \& Louër, D. (1991). J. Appl. Cryst. 24, 987993.

Brandenburg, K. (1998). DIAMOND, Version 2.0h. Crystal Impact GbR, Bonn, Germany.

Brehm, L., Krogsgaard-Larsen, P., Johnston, G. A. R. \& Schaumberg, K. (1976). Acta Chem. Scand. B, 30, 542-548.
Cuervo, J., Rincón, L., Almeida, R., Mora, A. J., Delgado, G. \& Bahsas, A. (2002). J. Mol. Struct. 615, 191-199.

David, W. I. F., Shankland, K., Cole, J., Maginn, S., Motherwell, W. D. H. \& Taylor, R. (2001). DASH User Manual. Cambridge Crystallographic Data Centre, Cambridge, UK.

De Wolff, P. M. (1968). J. Appl. Cryst. 1, 108-113.

Delgado, G., Mora, A. J. \& Bahsas, A. (2001). Acta Cryst. C57, 965967.

Finger, L. W., Cox, D. E. \& Jephcoat, A. P. (1994). J. Appl. Cryst. 27, 892-900.

Fitch, A. N. (1996). Mater. Sci. Forum, 228-231, 219-222.

Fitch, A. N. (2004). J. Res. Natl. Inst. Stand. Technol. 109, 133142.

Glusker, J. P. (1996). The Crystal as a Supramolecular Entity, Vol. 2, edited by G. R. Desiraju, ch. 6. London: John Wiley and Sons.

Jensen, J. H. \& Gordon, M. S. (1995). J. Am. Chem. Soc. 117, 81598170.

Laar, B. van \& Yelon, W. B. (1984). J. Appl. Cryst. 17, 4754.

Larson, A. C. \& Von Dreele, R. B. (2001). GSAS, General Structure Analysis System. Los Alamos National Laboratory, Los Alamos, New Mexico, USA.

Mó, O., Yañez, M. \& Elguero, J. (1992). J. Chem. Phys. 97, 6628-6638. Mó, O., Yañez, M., Rozas, J. \& Elguero, J. (1994). Chem. Phys. Lett. 219, 45-52.

Mora, A. J., Delgado, G., Ramírez, B., Cuervo, J., Rincón, L., Almeida R. \& Bashas, A. (2002). J. Mol. Struct. 615, 201-208.

Nagy, P. I. \& Noszl, B. (2000). J. Phys. Chem. A, 104, 68346843.

Rietveld, H. M. (1969). J. Appl. Cryst. 2, 65-71.

Rincón, L., Almeida, R., García-Aldea, D. \& Diez y Riega, H. (2001). J. Chem. Phys. 114, 5552-5563.

Smith, G. S. \& Snyder, R. L. (1979). J. Appl. Cryst. 12, 60-65.

Spek, A. L. (2003). J. Appl. Cryst. 36, 7-13.

Stephens, P. W. (1999). J. Appl. Cryst. 32, 281-289.

Tajkhorshid, E., Jalkanen, K. J. \& Suhai, J. S. (1998). Phys. Chem. B, 102, 5899-5913.

Toby, B. H. (2001). J. Appl. Cryst. 34, 210-213. 